\title{
Water strategy based on multi-objective planning and Combination incentive game theory \\ Wan-Sheng Liu
}

School of North China Electric Power University, Baoding 071000, China;

15733228620@163.com

Keywords: water strategy, interbasin water transfer, Game Theory

Abstract : In this paper, two models are built to solve the water scarcity problem, from which 1.6 billion people are suffering. In order to improve the water scarcity situation, an interbasin water transfer model and an agricultural water-saving model are built.

\section{Introduction}

Water is the origin of life. Water is the gift which god has given us, there is no water, and humans will not be able to survive. As the economy grows, the demand of water is more and more big. However, water has evolved into the bottleneck, which severely restricts the development of a region, a country, even the global [1]

\section{Interbasin water transfer model}

The interbasin water transfer model is built to alleviate the water shortage condition, using the method transferring water from abundant region to deficient region. To realize the goal, what we can do is to balance the supply and demand water in the time-space relation and total flow. Based on the above analysis, we can construct a decision making system, and Fig. 1 is the schematic diagram of water diversion.

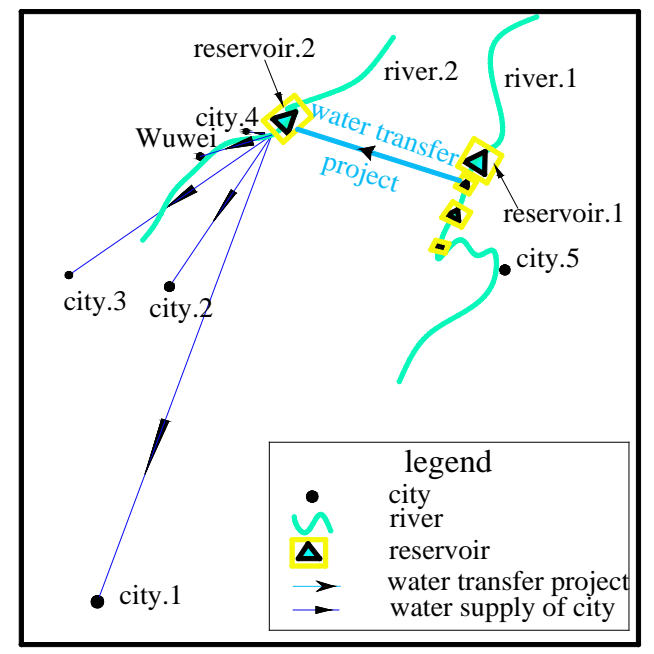

Fig.1 schematic diagram of water diversion

In order to further study on the interbasin water transfer, we build the multi-objective programming model first, based on the multi-objective and multi-level theory of large scale system.

According to the optimal allocations of water resources, we divide the region into two levels, named region and sub-region. Also, the decision variable Q1(i, k), Q1(i, k), Q1(i, k), Q1(i, k) stands for the public water allocating to user $k$ of region $i$, local public water resources, local superficial water, local underground water, respectively. For sake of convenience, we assume that the users include industry, agriculture, life, ecology.

Build the objective functions of sub-regions as follows. 


$$
\left\{\begin{array}{l}
\min \left\{Z_{i 1}\right\}=\min \left\{\sum_{k=1}^{4}\left[U(i, k)-Q_{1}(i, k)-Q_{2}(i, k)-Q_{3}(i, k)-Q_{4}(i, k)\right]\right\} \\
\max \left\{Z_{i 2}\right\}=\max \left\{\sum_{k=1}^{4} b(i, k)\left[Q_{1}(i, k)+Q_{2}(i, k)+Q_{3}(i, k)+Q_{4}(i, k)\right]\right\} \\
\min \left\{Z_{i 3}\right\}=\min \left[\sum_{k=1}^{4} Q_{4}(i, k)\right]
\end{array}\right.
$$

where $\mathrm{U}(\mathrm{i}, \mathrm{k})$ represents the water requirement of user $\mathrm{k}$ of region i considering the water transfer, $b(i, k)$ is the coefficient of net contribution, $Z_{i 1}$ represents the water deficit per year of region $i, Z_{i 2}$ is the net contribution per year of region $\mathrm{i}, \mathrm{Z}_{\mathrm{i} 3}$ represents the production volume of underground per year.

The objective functions of regional level are built here.

$$
\left\{\begin{array}{l}
\min \left\{Z_{1}\right\}=\min \sum_{k=1}^{m}\left\{\sum_{k=1}^{4}\left[U(i, k)-Q_{1}(i, k)-Q_{2}(i, k)-Q_{3}(i, k)-Q_{4}(i, k)\right]\right\} \\
\max \left\{Z_{2}\right\}=\max \sum_{k=1}^{m}\left\{\sum_{k=1}^{4} b(i, k)\left[Q_{1}(i, k)+Q_{2}(i, k)+Q_{3}(i, k)+Q_{4}(i, k)\right]\right\} \\
\min \left\{Z_{3}\right\}=\min \sum_{k=1}^{m}\left[\sum_{k=1}^{4} Q_{4}(i, k)\right]
\end{array}\right.
$$

where the $\mathrm{Z}_{1}, \mathrm{Z}_{2}, \mathrm{Z}_{3}$ represent the gross water requirement of this region considering water transfer, net contribution, the production volume of underground per year, respectively.

Towards the objective functions above, there are many restraints, the balance of all kinds of available water, water capacity of this region etc, included.

\section{Combination incentive game theory model}

Refer to the information, if agricultural water-saving measures are fully promoted, water efficiency of irrigation will reach $0.72[2]$. The main agricultural water-saving measures are showed in Figure.2.

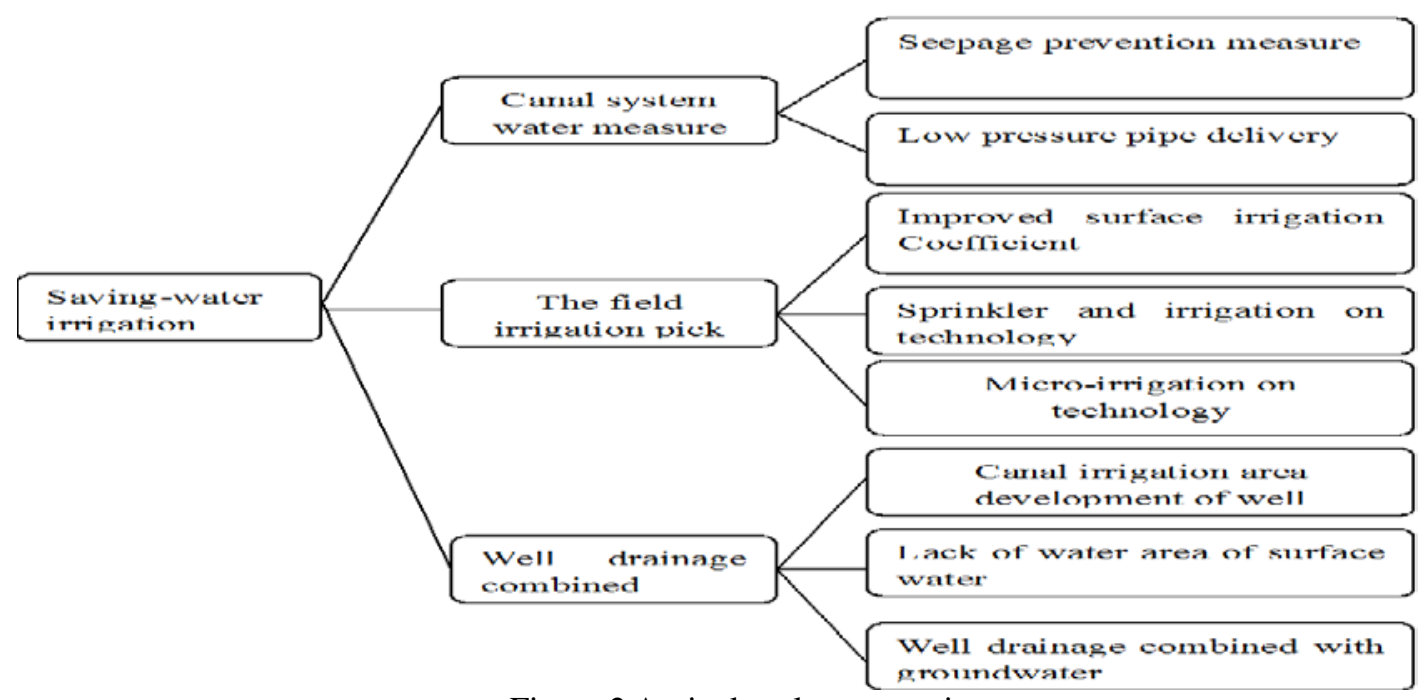

Figure.2 Agricultural water saving measures

In order to verify the feasibility of promoting water-saving measures, the combination incentive game model is taken.

\section{Analysis between government and peasant}

The game between government and peasant is showed in Tab.1, where $Z_{1}, Z_{2}, Z_{3}$, and $Z_{4}$ represent government's revenue, $N_{1}, N_{2}, N_{3}$, and $N_{4}$ stand for the farmers' income, and $n$ is the subsidies of government for farmers to use water-saving irrigation. $Z_{4}>Z_{3}, Z_{2}>Z_{1}$, The government uses the high water price, and carries on the subsidy to farmers who Adopt water saving irrigation. As long as $N_{4}+n>N_{3}$, farmers must use water-saving irrigation methods. The use of water-saving 
irrigation improves the production of agricultural products, providing tax revenue for the government indirectly, and on the other hand the government acquires the social benefits by means of saving water. So the government is willing to subsidize, so to achieve the Nash equilibrium.

Tab.1 the game between government and peasant

\begin{tabular}{lll}
\hline Item & Low water price & High water price \\
\hline No-water-saving irrigation & $\left(\mathrm{N}_{1}, \mathrm{Z}_{1}\right)$ & $\left(\mathrm{N}_{3}, \mathrm{Z}_{3}\right)$ \\
Water-saving irrigation & $\left(\mathrm{N}_{2}, \mathrm{Z}_{2}\right)$ & $\left(\mathrm{N}_{4}+\mathrm{n}, \mathrm{Z}_{4}-\mathrm{n}\right)$ \\
\hline
\end{tabular}

\section{Analysis between government and manufacturer}

The game between government and peasant is showed in Tab.2, where $S, S+a, S+b-c_{1}$, and $\mathrm{S}+\mathrm{b}_{1}-\mathrm{C}_{2}+\mathrm{a}$ represent the profits of manufactures, and $\mathrm{T}, \mathrm{T}+\mathrm{a}$, and $\mathrm{T}-\mathrm{a}+\mathrm{b}_{2}$ stand for government's revenue, $\mathrm{c}$ is the cost of agricultural water-saving equipment manufacturers to carry out technological innovation, a is the subsidies of government for manufactures to carry out technological innovation, and $\mathrm{b}$ is the cost of agricultural water-saving equipment manufacturers to carry out technological innovation. As long as government carries on the subsidy to manufactures, making b1-c2+a $>0$, which can be done, Manufacturers must innovate technology. The government will gain some new revenue, so the government is willing to subsidize.

Tab.2 the game between government and manufacture

\begin{tabular}{lll}
\hline Item & No allowance & Allowance \\
\hline NO innovation & $(\mathrm{S}, \mathrm{T})$ & $(\mathrm{S}+\mathrm{a}, \mathrm{T}+\mathrm{a})$ \\
Innovation & $\left(\mathrm{S}+\mathrm{b}_{1}-\mathrm{c}_{1}, \mathrm{~T}\right)$ & $\left(\mathrm{S}+\mathrm{b}_{1}-\mathrm{c}_{2}+\mathrm{a}, \mathrm{T}-\mathrm{a}+\mathrm{b}_{2}\right)$ \\
\hline
\end{tabular}

\section{Combination incentive game}

In order to promote agricultural water-saving technology, it is necessary to subsidize peasant and manufacture. The incentive game is showed in Figure.3. The incentive game is based on Tab.1 and.Tab.2. From the first node to the last node, the profits of manufacture is $S+b_{1}-c_{2}+a$, and the profits of peasant is $\mathrm{N}_{4}+n$. The profits reach the best equilibrium. From combination of incentives, the profits are likely to have new positive increase. Because manufacturers and farmers cooperation under the government stimulus will reduce water saving irrigation technology promotion costs, which is more likely to promote the promotion of agricultural irrigation technology

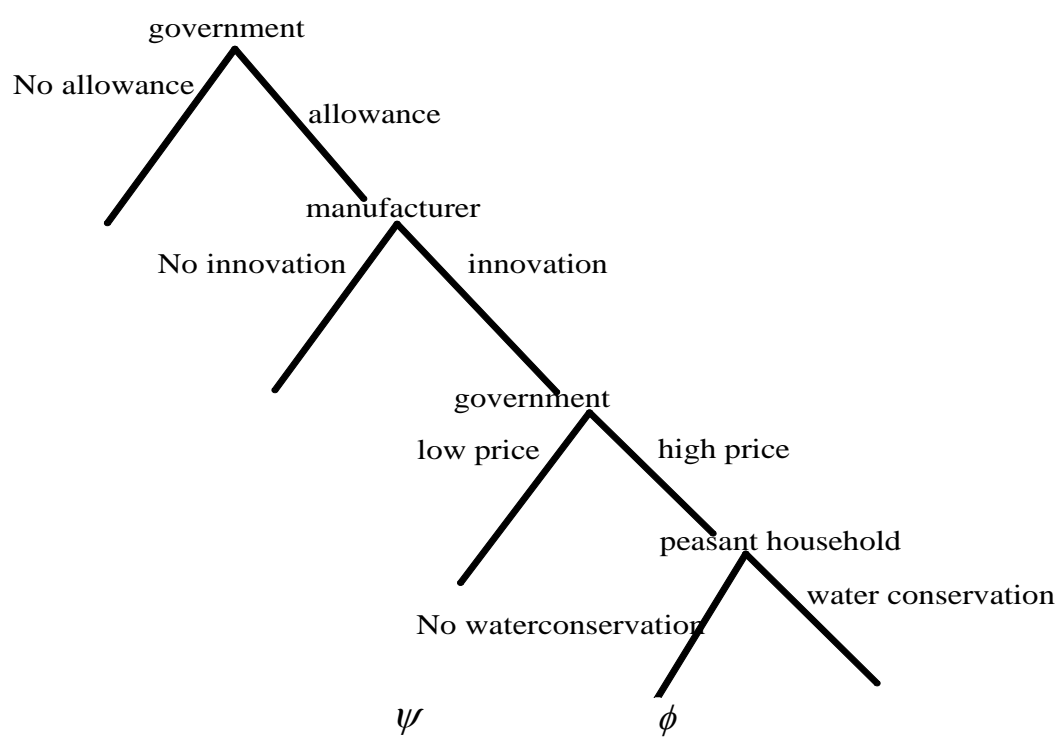

Fig.3 combination incentive game

Where $\phi$ and $\psi$ represent the profits of manufacture and the profits of peasant. 


\section{Summary}

According to the United Nations, Water use has been growing at twice the rate of population over the last century. Human facing a water crisis, Human beings must set up water-saving awareness. In order to alleviate this situation, two feasible strategies is put forward in this paper. The model of interbasin is built considering the economic, social, and environmental benefits. Agricultural water saving irrigation is safeguard measures of the sustainable development of agriculture in our country. The government's combination incentive of farmers and water-saving irrigation equipment manufacturers can promote agricultural water saving better.

\section{References}

[1] Daniele Cesano, Jan-Erik Gustafsson,” Impact of economic globalization on water resources: A source of technical, social and environmental challenges for the next decade,” Water Policy, vol.2, No.3, pp.213-227, 14 July 2000.

[2] Thenkabail, P.S., "Improving Water Productivity for Agriculture-Predicting and Preventing Crisis in Irrigated Water Use in a Changing Climate” Global Humanitarian Technology Conference (GHTC), 2011 IEEE, vol., no., pp.176-176, 30 Oct 2011. 